\title{
National cord blood bank opens first sites in Ottawa
}

A week after opening, Canada's first national public cord blood bank had collected 40 units of cord blood, on its way to a target over the next six years of 18000 units containing potentially life-saving stem cells for patients in need of transplants.

The first collection sites opened in Ottawa, Ontario, at The Ottawa Hospital's General and Civic campuses, where mothers who had newly delivered babies were for the first time able to contribute umbilical cord blood and store it in a bank that the Canadian Blood Services is running to benefit anyone in need.

"Generally, it's been very positive," Ann Mitchell, director of maternal newborn services at The Ottawa Hospital, said of the reception from women during the first week of donations.

Stem cells drawn from donated umbilical cord blood can be used to treat more than 50 diseases, including, most commonly, aplastic anemia and blood cancers such as leukemia and lymphoma. Stem cell donors and recipients are matched using human leukocyte antigens (HLA) tissue typing. Stem cells drawn from cord blood require less stringent matching of HLAs than do cells drawn from bone marrow or peripheral blood, resulting in more frequent successful matches, says Dr. Heidi Elmoazzen, director of the cord blood bank. They can also be stored indefinitely in cryopreservation.

Even so, almost 1000 patients in Canada are currently waiting for stem cell transplants, and three-quarters of them have to look outside their own families for an appropriate match, Elmoazzen says.

Previously, patients in need of stem cell transplants had to search for potential matches from among the almost 600000 cord blood units stored in public banks around the world. But because of Canada's unique ethnic diversity, Canadian Blood Services is unable to find matches for half of its waiting patients, says Elmoazzen. First Nations

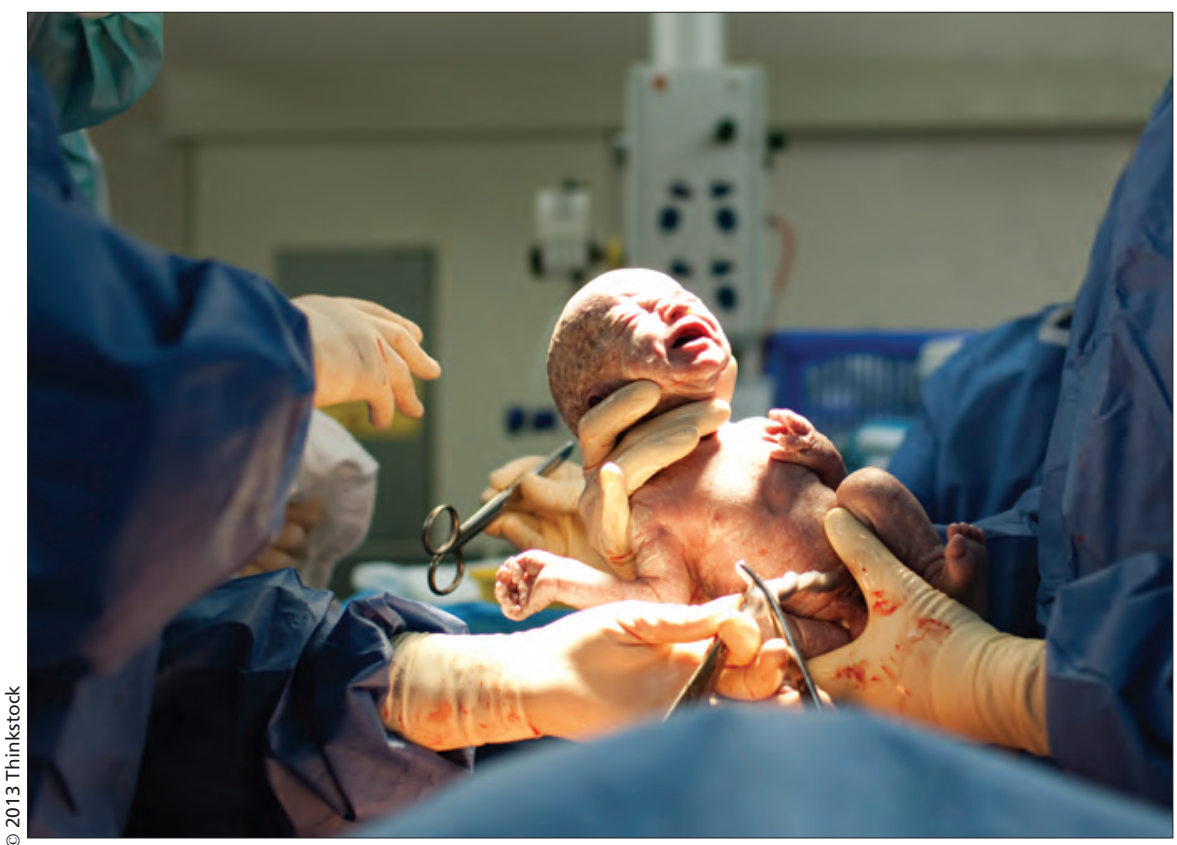

Stem cells drawn from donated umbilical cord blood can be used to treat more than $\mathbf{5 0}$ diseases, including aplastic anemia and blood cancers such as leukemia .

and Métis patients have a particularly tough time finding matches, she says.

"That's why building a bank that's reflective of our ethnic diversity in Canada is going to be critical," says Elmoazzen.

The new cord blood bank, which opened Sept. 30, will expand by mid2014 to include collection sites at hospitals in Vancouver, British Columbia; Edmonton, Alberta; and Brampton, Ontario. Canadian Blood Services chose those cities and partner hospitals specifically to try to collect cord blood from as diverse an ethnic population as possible.

It costs the Canadian health care system $\$ 42000$ to buy just one unit of cord blood from an international cord blood bank - and most adults requiring stem cell transplants need two units, Elmoazzen says. That's one of the reasons the provinces and territories (except Quebec) kicked in \$35.5 million to finance the new bank, with Canadian Blood Services committing to raising another $\$ 12.5$ million from a public outreach campaign, for a total of $\$ 48$ million. So far, the campaign, called For All Canadians, has raised $\$ 6.3$ million.

When enough donations are banked, both Canadian transplant physicians and international physicians will be able to search it for a match for waiting patients, Elmoazzen says. International users will be charged for the units they need, just as Canadian users are when they use cord blood from international banks. Matches are made according to the closest HLA tissue typing, regardless of whether the person who needs the stem cell transplant is in Canada or elsewhere.

Canadian Blood Services has distributed more than 10000 information booklets about cord donation to physicians and midwives in the Ottawa area so far, so that pregnant women can learn about what is involved in donating and will hopefully consent ahead of arriving at the hospital. Any healthy woman who is 34 weeks or more into her pregnancy when she delivers, and is delivering a single baby, can donate her umbilical cord blood, which would otherwise be disposed of as medical waste. 
Elmoazzen does not anticipate any problem in reaching the goal of collecting 18000 units over the next six years, she says.

"Public cord blood banking is quite an easy sell since the umbilical cord and placenta are usually discarded," she says. "They don't really have to do anything."

In a pilot program to test and build the system, women delivering at The
Ottawa Hospital donated 950 units even though they knew those units would not be stored, says Mitchell. "So I think there's a lot of interest from women and families in the community to contribute to the public cord bank," she says.

Previously, there were two provincial public cord blood banks in Canada Héma Quebec and the Alberta Cord Blood Bank. There are also smaller public cord blood banks, such as the Victoria Angel Cord Blood Bank at the Markham-Stouffville Hospital in Markham, Ontario. In addition, private cord blood banks allow families to bank their own child's blood after paying an initial collection fee plus an annual storage charge. — Laura Eggertson, CMAJ

\section{A home for interprofessional medical education at Dalhousie}

$\mathrm{D}$ alhousie University in Halifax, Nova Scotia, is constructing a building where students from different health disciplines will learn together both inside and outside of the classroom to better prepare them for working as part of health care teams.

"Traditionally, the education of students in these programs has been siloed," says William Webster, dean of the university's Faculty of Health Professions. "This is a real problem. In evolving health care delivery, there is an emphasis on team delivery."

The five-storey, \$35-million building is in keeping with a shift in the curricula at the university's Centre for Collaborative Health Education, which has been evolving to better prepare students for team-based professional environments.

Currently, students in health disciplines learn in buildings scattered across campus or in leased space throughout Halifax, making some types of interprofessional education difficult.

The new building will allow faculty to teach future health professionals, including students of medicine, nursing, physiotherapy and social work, in the same location. The students will still learn most things separately, but when curriculum overlaps educators can arrange lectures, interprofessional projects or case studies to help students learn about other professions' perspectives and approaches.

The building will also house a simulation lab, where students from different disciplines can practise using each other's skillsets and competencies to provide patients with the best possible care.

Shares social spaces in the building will also encourage social mingling outside of schoolwork, says Webster.

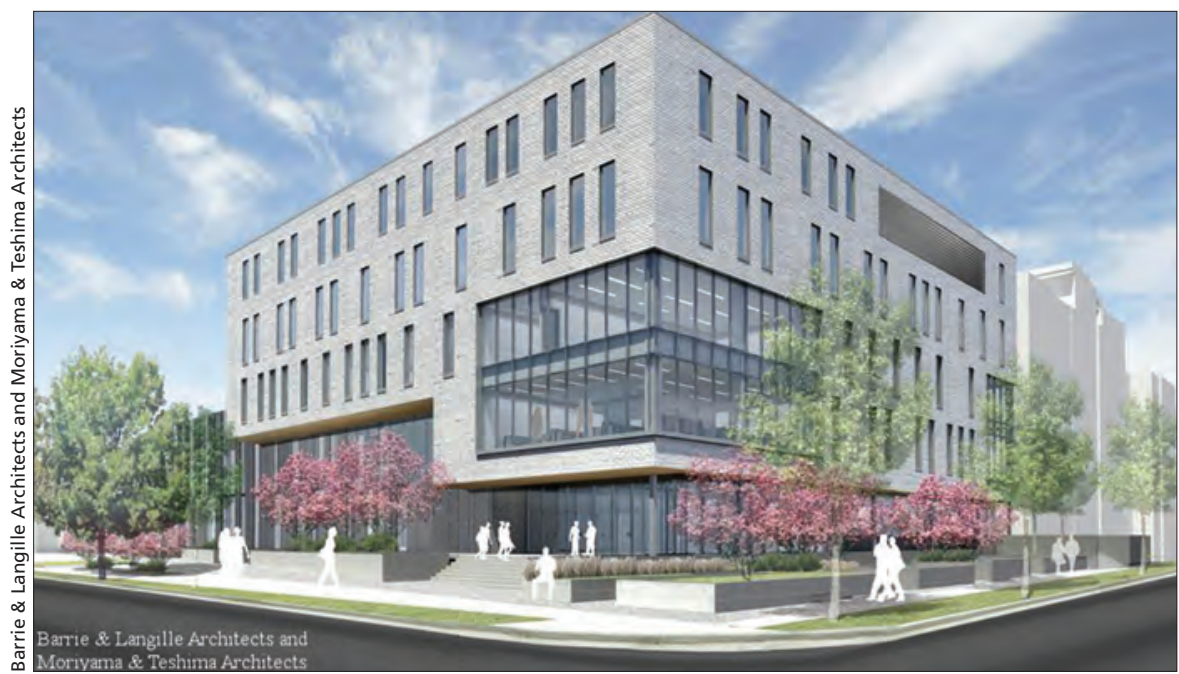

Artist's rendering of Dalhousie University's planned Collaborative Health Education Building.

"It's really about helping students understand very early on what each profession does," he says. "We're trying to instill the concept of patient and family-centred care."

Dalhousie already has a health mentors program, established in 2010, that places students in interprofessional groups of four. Each group spends time with a volunteer mentor who has a chronic health condition. The students learn how these conditions affect their mentors' daily lives as well as what it's like to navigate the health care system.

As students do this, they work on patient-centred care approaches, effective interviewing and active listening.

They also gain a better understanding of their team members' roles.

Dalhousie's curriculum is becoming increasingly interprofessional, says Alison McIntyre, a former occupational therapist who is now a second-year medical student. She represents the Dal- housie Medical Student Society at curriculum meetings and sees the building as an important step in this transition.

"It's great," she says. "Collaborative teams are the way of the future."

Students from different disciplines currently work together on group projects when their respective curricula overlap. For example, students studying occupational therapy work with social work students to make a poster that addresses an issue in their community.

The Nova Scotia government has pledged $\$ 10$ million over the next 15 years to support the building's construction and operating costs. The building will welcome its first students in September 2015.

"Interprofessional education really fits in with the government's policy on how they want health care delivery to operate," says Webster. - Catherine Cross, CMAJ

CMAJ 2013. DOI:10.1503/cmaj.109-4632 